\title{
Trichofolliculoma of the eyelid: systematic review
}

\author{
Kevin Phan ${ }^{1,2^{*}}$ (D) Sourabh Goyal ${ }^{3}$, Erica Ahn ${ }^{4}$, Leo Kim ${ }^{5}$ and Deshan Frank Sebaratnam ${ }^{1,2,5}$
}

\begin{abstract}
Background: Trichofolliculoma of the eyelid and periorbital region remains is rare, and there is limited evidence regarding surgical management, clinical and histological margins, and recurrence rate.

Objectives: We performed a systematic review of cases to date on diagnosis and management outcomes of eyelid trichofolliculoma.

Methods: Electronic databases were searched for cases reported on trichofolliculoma of the eyelid. The authors extracted and collated data from these studies, and outcomes were summarized descriptively.

Results: One hundred twenty citations were identified from database searching. The authors also report a case of eyelid trichofolliculoma. Fifteen studies reporting 19 cases of eyelid trichofolliculoma were finally included. Eighteen out of 19 (94.7\%) cases were treated with surgical excision. Of 5 cases which were followed up over an average of 2 years, there was only 1 case of recurrence requiring wedge resection.

Conclusions: Recurrence rate in patients with eyelid trichofolliculoma excised with satisfactory margins appears to be low, and no cases of malignant transformation have been reported.
\end{abstract}

Keywords: Trichofolliculoma, Eyelid, Ocular, Periorbital, Surgical excision

\section{Introduction}

Trichofolliculoma is a rare benign skin hamartoma of the pilosebaceous follicle, often seen in younger patients with predilection for face and scalp, with some rare cases affecting the eyelid (Simpson et al. 1989; Ozdal et al. 2003; Taniguchi \& Hamada. 1996). They often present as small nodules, with single or multiple hairs protruding onto the epidermal surface from a single pilosebaceous orifice. Although there are a number of dermatological pathologies that can be found on the eyelid and be treated surgically (Hu et al. 2017; Kohli \& Bordeaux. 2019; Martínez-Palmer et al. 2017), there is a rarity of such literature for eyelid trichofolliculoma. Given the scarcity of published cases on eyelid trichofolliculoma, there is limited understanding regarding the recurrence rates and ideal surgical margins required for treatment.

To assess the limitations in the current evidence, we performed a systematic review of all cases of trichofolliculoma

\footnotetext{
* Correspondence: kphan.vc@gmail.com

'Department of Dermatology, Liverpool Hospital, Elizabeth St, Sydney, Australia

${ }^{2}$ Faculty of Medicine, University of New South Wales, Kensington, Australia Full list of author information is available at the end of the article
}

of the eyelid. We also included the clinical and pathological features of a case report from our institution as part of the systematic review of cases.

\section{Methods and methods \\ Search strategy for systematic review}

The present systematic review was performed according to the recommended PRISMA guidelines. This study did not involve humans or animals and only uses previously published data, as such the requirement for ethics approval was waived. Electronic searches were performed using Ovid MEDLINE, PubMed, Cochrane Central Register of Controlled Trials (CCTR), Cochrane Database of Systematic Reviews (CDSR), ACP Journal Club, and Database of Abstracts of Review of Effectiveness (DARE) from their dates of inception to 24 May 2018. To achieve the maximum sensitivity of the search strategy, we combined the terms "trichofolliculoma," "eye," "eyelid," and "ocular," as either keywords or MeSH terms. The reference lists of all retrieved articles were reviewed for further identification of potentially relevant 


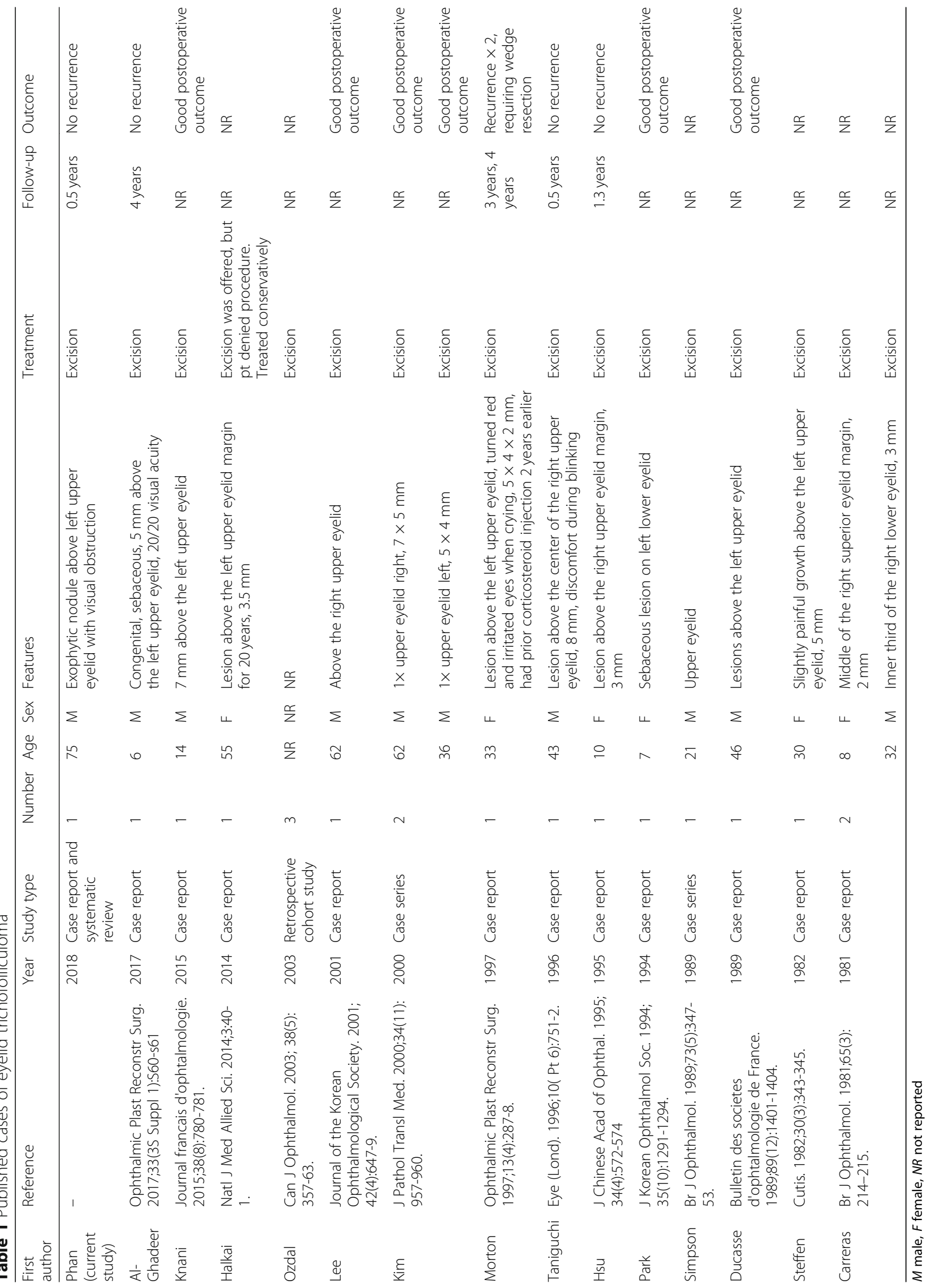


studies, assessed using the inclusion and exclusion criteria.

\section{Selection criteria}

Eligible studies for the present systematic review included those in which patients were reported to have a histologically confirmed diagnosis of trichofolliculoma of the eyelid or near the eyelid margins. Case reports and case series were included, and there were no language restrictions. Abstracts, conference presentations, editorials, reviews, and expert opinions were excluded. Review articles were omitted because of potential publication bias and duplication of results.

\section{Data extraction and statistical analysis}

All data were extracted from article texts, tables, and figures. Two investigators independently reviewed each retrieved article (K.P, S.G). Discrepancies between the two reviewers were resolved by discussion and consensus. Data was subsequently reviewed and tabulated. Descriptive analyses were performed and presented as mean \pm standard deviation or as fraction (\%) where appropriate. The final results were reviewed by the senior author (D.F.S).

\section{Results}

\section{Systematic review}

A total of 120 references were identified through electronic database searches. After exclusion of duplicate or irrelevant references, 19 potentially relevant articles were retrieved. After detailed evaluation of these articles, 11 studies remained for assessment. Manual search of reference lists yielded 3 new studies. After applying the selection criteria, 14 studies (Simpson et al. 1989; Ozdal et al. 2003; Taniguchi \& Hamada. 1996; Al-Ghadeer and Edward, 2017; Knani et al. 2015; Halkai et al. 2014; Lee and Yim, 2001; Kim et al. 2000; Morton et al. 1997; Hsu et al. 1995; Park et al. 1994; Ducasse et al. 1989; Steffen \& Leaming. 1982; Carreras Jr. et al., 1981) and the present case report were selected for analysis (Additional file 1: Figure S1). The study characteristics of these studies are summarized in Table 1.

A total of 15 publications reporting 19 individual case reports of eyelid trichofolliculoma were identified, including one case at our institution in the present publication. This was a 75-year-old man presented with a 10-year history of an exophytic nodule of the left upper eyelid with associated visual obstruction (Fig. 1). An initial snip biopsy demonstrated a large, dilated, and plugged central hair follicle from which many secondary follicles radiated into the surrounding densely fibrotic stroma. The patient proceeded to surgical extirpation by a plastic surgeon. The dermis was expanded by tumoral process composed of multiple varying sized hair follicles in a cellular fibrous stroma. Dilated infundibula were noted

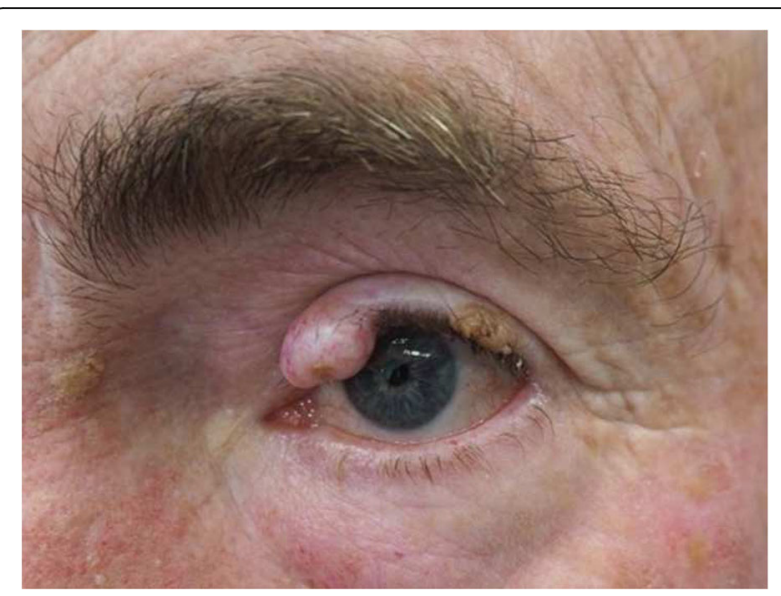

Fig. 1 A 75-year-old man presented with a 10-year history of an exophytic papule of the left upper eyelid with visual obstruction

with foci of calcification visualized within the lesion and the surrounding dermis and within the lesions. The pathology was consistent with trichofolliculoma (Fig. 2).

The average age of patients with eyelid trichofolliculoma in the literature was 33.8 years. Ten out of 16 $(62.5 \%)$ cases were male, and three cases described in one study did not report the sex of the cases. All cases were located on or above the upper eyelid margin except for one (Park et al. 1994), which was located on the lower eyelid. Of 14 cases that reported laterality, 8 (57.1\%) were located on the left side. Eighteen out of 19 (94.7\%) were surgically extirpated, with one single case (Halkai et al. 2014) where treatment was declined by the patient and was treated conservatively. Of 5 cases which were followed up over an average of 2 years, there was only 1 case of recurrence (Morton et al. 1997). For this particular case, recurrence had occurred two times after two excisional biopsy procedures. A wedge resection was required to be performed with good effect.

\section{Discussion}

Trichofolliculoma is a rare adnexal tumor, and only a handful of cases have been reported affecting the eyelid. Typically, trichofolliculoma presents as a single pink-to-flesh colored, dome-shaped papule or nodule with well-defined margins on the face, with size varying from $2 \mathrm{~mm}$ to $1.8 \mathrm{~cm}$ in diameter. It is common, although not compulsory or pathomneumonic, to find wool-like wisps of immature hairs emerging from the central orifice of the trichofolliculoma. These tumors normally follow an indolent clinical course, but surgical intervention may be needed in symptomatic cases or where there is a functional or cosmetic impairment. 


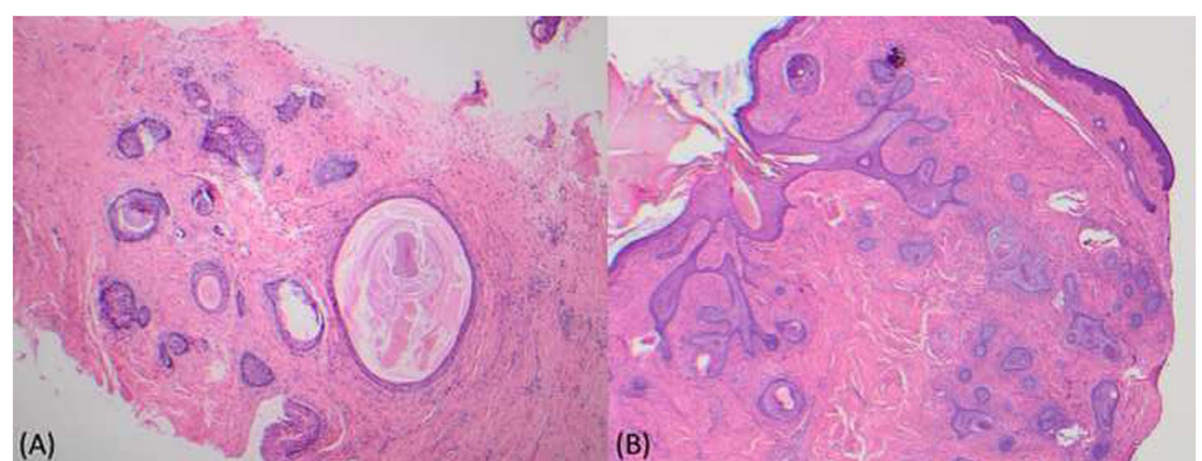

Fig. 2 a Initial snip biopsy demonstrated a large, dilated, and plugged central hair follicle from which many secondary follicles radiated into the surrounding densely fibrotic stroma. $\mathbf{b}$ Excisional biopsy histopathology demonstrating a large, dilated, and plugged central hair follicle from which many secondary follicles radiated into the surrounding fibrotic stroma, consistent with trichofolliculoma

Other pathological differential diagnoses for basaloid follicular tumors include trichoepithelioma, trichoadenoma, and basal cell carcinoma. Aside from histological appearance, these pathologies can also be differentiated by their expression profiles (Kurokawa et al. 2005). Trichoadenoma expresses cytokeratins 10 and 15 and trichofolliculoma expresses cytokeratin (Ducasse et al. 1989; Steffen \& Leaming. 1982; Carreras et al. 1981), whereas trichoepithelioma only expresses cytokeratin (Ducasse et al. 1989, Kurokawa et al. 2005). Trichofolliculoma may stain CD34 positive, whilst basal cell carcinomas are negative for CD34 staining (Kohli \& Bordeaux. 2019). Histological appearance will also rule out hair follicle nevus and folliculosebaceous cystic hamartomas.

Our systematic review identified another 18 cases of eyelid trichofolliculoma from the published literature. There was no significantly predilection for either sex or either left versus right eyelid. The majority of cases were associated with the upper eyelid margin, rather than lower eyelid margin. All cases except one were treated with surgical excision with good effect. One case report described multiple recurrences of the trichofolliculoma, eventually requiring wedge resection with good effect (Morton et al. 1997). However, there have not been any other documented cases of recurrence if the original trichofolliculoma was adequately excised or biopsied. As such, the recurrence rate in patients with eyelid trichofolliculoma excised with satisfactory margins appears to be low. This is in keeping with trichofolliculoma at other sites.

\section{Conclusion}

To date, there have been no cases of malignant transformation of trichofolliculomas. Although benign, dermatologists, ophthalmologists, and plastic surgeons should be aware of the clinical features and management of trichofolliculomas and have this as a differential diagnosis for skin lesions on the eyelid margins.

\section{Supplementary information}

Supplementary information accompanies this paper at https://doi.org/10. 1186/s41702-019-0055-X.

Additional file 1: Figure S1. PRISMA flow chart of search strategy

\section{Acknowledgements}

Not applicable

\section{Authors' contributions}

$K P$ and DS designed the study. KP, EA, LK, and DS collected the data. KP, EA, LK, and DS analyze the data. KP, SG, and DS drafted the manuscript. All authors contributed to the final review. All authors read and approved the final manuscript.

\section{Funding}

Not applicable

\section{Availability of data and materials}

All data are available in the manuscript.

\section{Ethics approval and consent to participate}

Not applicable. Institutional ethics approval waived as single patient case report, de-identified. Written informed consent was obtained from the patient for the publication of their individual details and accompanying images in this manuscript. The consent form is held by the authors/by the authors' institution and is available for review by the Editor-in-Chief.

\section{Consent for publication}

Written informed consent was obtained from the patient for publication of their individual details and accompanying images in this manuscript. The consent form is held by the authors/by the authors' institution and is available for review by the Editor-in-Chief upon request.

\section{Competing interests}

The authors declare that they have no competing interests.

\section{Author details}

'Department of Dermatology, Liverpool Hospital, Elizabeth St, Sydney, Australia. 'Faculty of Medicine, University of New South Wales, Kensington, Australia. ${ }^{3}$ Lake Erie College of Osteopathic Medicine, Erie, PA, USA. ${ }^{4}$ Douglass Hanly Moir Pathology, Sydney, Australia. ${ }^{5}$ The Skin Hospital, Sydney, Australia. 
Received: 7 August 2019 Accepted: 25 November 2019

Published online: 07 January 2020

\section{References}

Al-Ghadeer H, Edward DP. Congenital sebaceous trichofolliculoma of the upper eyelid. Ophthalmic Plast Reconstr Surg. 2017:33(3S Suppl 1):S60-s61.

Carreras B Jr, Lopez-Marin I Jr, Mellado VG, Gutierrez MT. Trichofolliculoma of the eyelid. Br J Ophthalmol. 1981;65(3):214-5.

Ducasse A, Erhart G, Desphieux JL, Segal A, Pluot M. Benign tumor of pilar origin of the upper eyelid. Apropos of a case. Bulletin des societes d'ophtalmologie de France. 1989;89(12):1401-4.

Halkai SS, Badad AS, Kannur A, Halkai SA, Halkai JS. A rare case of trichofolliculoma involving eyelid margin. Natl J Med Allied Sci. 2014;3:40-1.

Hsu WM, Lee AF, Yang TT. Trichofolliculoma of eyelid - case report. J Chinese Acad of Ophthal. 1995;34(4):572-4

Hu L, Jin Y, Tremp M, Lin X. Reconstruction of a large divided nevus of the eyelid. Dermatol Surg. 2017;43(12):1483-6.

Kim KM, Ko JK, Lee A, Kang CS, Kim BK, Kang SJ. Trichofolliculoma in Korean patients: a report of six cases. J Pathol Transl Med. 2000;34(11):957-60.

Knani L, Ben Abdelkarim S, Ben Rayana N, Ben Hadj Hamida F, Mokni M. Trichofolliculoma of the eyelid. Journal francais d'ophtalmologie. 2015;38(8): 780-1.

Kohli N, Bordeaux JS. Repair of a full-thickness defect of the lower eyelid margin. Dermatol Surg. 2019:45(6):845-7.

Kurokawa I, Mizutani H, Nishijima S, Kato N, Yasui K, Tsubura A. Trichoadenoma: cytokeratin expression suggesting differentiation towards the follicular infundibulum and follicular bulge regions. Br J Ophthalmol. 2005;153(5): 1084-6.

Lee SH, Yim HB. Trichofolliculoma in the upper eyelid. J Korean Ophthalmol Soc. 2001:42(4):647-9.

Martínez-Palmer A, Calsina-Prat M, Ormaechea N, Toll A. Reconstruction of combined upper and lower eyelid defects in a patient with lentigo maligna. Dermatol Surg. 2017:43(Suppl 1):S111-4.

Morton AD, Nelson CC, Headington JT, Elner VM. Recurrent trichofolliculoma of the upper eyelid margin. Ophthalmic Plast Reconstr Surg. 1997;13(4):287-8.

Ozdal PC, Callejo SA, Codere F, Burnier MN Jr. Benign ocular adnexal tumours of apocrine, eccrine or hair follicle origin. Can J Ophthalmol. 2003;38(5):357-63.

Park HC, Lee HB, Oh SJ. A case of sebaceous trichofolliculoma in lower eyelid margin. J Korean Ophthalmol Soc. 1994;35(10):1291-4.

Simpson W, Garner A, Collin JR. Benign hair-follicle derived tumours in the differential diagnosis of basal-cell carcinoma of the eyelids: a clinicopathological comparison. Br J Ophthalmol. 1989;73(5):347-53.

Steffen C, Leaming DV. Trichofolliculoma of the upper eyelid. Cutis. 1982;30(3): 343-5.

Taniguchi S, Hamada T. Trichofolliculoma of the eyelid. Eye (Lond). 1996;10(Pt 6): $751-2$.

\section{Publisher's Note}

Springer Nature remains neutral with regard to jurisdictional claims in published maps and institutional affiliations.

Ready to submit your research? Choose BMC and benefit from:

- fast, convenient online submission

- thorough peer review by experienced researchers in your field

- rapid publication on acceptance

- support for research data, including large and complex data types

- gold Open Access which fosters wider collaboration and increased citations

- maximum visibility for your research: over $100 \mathrm{M}$ website views per year

At $\mathrm{BMC}$, research is always in progress.

Learn more biomedcentral.com/submissions 